\title{
CROSS-CULTURAL ADAPTATION OF THE ADOLESCENT PEDIATRIC PAIN TOOL FOR BRAZILIAN CHILDREN AND ADOLESCENTS WITH CANCER
}

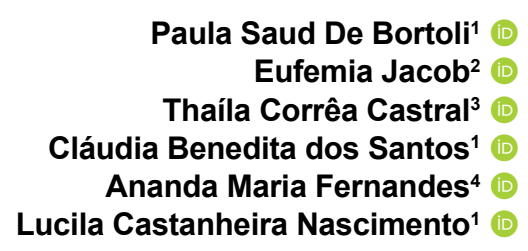

${ }^{1}$ Universidade de São Paulo, Escola de Enfermagem de Ribeirão Preto. Ribeirão Preto, São Paulo, Brasil. ${ }^{2}$ University of California, School of Nursing. Los Angeles, California, United States. 3universidade de Goiás, Faculdade de Enfermagem. Goiânia, Goiás, Brasil. ${ }^{4}$ Escola Superior de Enfermagem de Coimbra. Coimbra, Portugal.

\begin{abstract}
Objective: to describe the steps in the cross-cultural adaptation process of the Adolescent Pediatric Pain Tool, a pain assessment measure, for use with Brazilian children and adolescents with cancer. Method: a methodological and cross-sectional study was undertaken. The steps in the cross-cultural adaptation process of the tool that resulted in the semantic validation followed an adapted method, including: initial translation, consensus version of translations, evaluation by Expert Committee, back-translation, comparison with original tool and actual semantic validation.

Results: the initial translation process of the tool until the final consensus was reached took approximately four months. In the evaluation by the Expert Committee, three health professionals participated in the study, who were knowledgeable on the theme and mastered the English language. In the semantic validation, 35 children and adolescents aged between eight and 18 unfinished years participated, who were patients at the institution where children and adolescents with cancer were treated and monitored. After concluding all steps, the researchers met to discuss the proposed changes. At the end of the cross-cultural adaptation process of the Adolescent Pediatric Pain Tool, all initially proposed 67 pain descriptors were maintained in their Portuguese version.

Conclusion: the steps in the cross-cultural adaptation process of the Adolescent Pediatric Pain Tool were executed and described in detail, evidencing the rigorous development of the study.
\end{abstract}

DESCRIPTORS: Adolescent. Child. Neoplasms. Pain. Validation studies. 


\section{ADAPTAÇÃO CULTURAL DO INSTRUMENTO ADOLESCENT PEDIATRIC PAIN TOOL PARA CRIANÇAS E ADOLESCENTES BRASILEIROS COM CÂNCER}

\section{RESUMO}

Objetivo: descrever as etapas realizadas no processo de adaptação cultural do instrumento de avaliação da dor Adolescent Pediatric Pain Tool, para crianças e adolescentes brasileiros com câncer.

Método: trata-se de um estudo metodológico e transversal. As etapas percorridas do processo de adaptação cultural do instrumento até a validação semântica seguiram um método adaptado que compreendeu: tradução inicial, síntese das traduções, avaliação pelo Comitê de Especialistas, retrotradução, comparação com o instrumento original e validação semântica propriamente dita.

Resultados: o processo de tradução inicial do instrumento até a obtenção do consenso final levou, aproximadamente, quatro meses. Na etapa de avaliação pelo Comitê de Especialistas, participaram do estudo três profissionais da área da saúde, com conhecimento na temática e domínio da língua inglesa. Para a etapa de validação semântica, participaram 35 crianças e adolescentes de oito a 18 anos incompletos, atendidos na instituição onde eram realizados o tratamento e o seguimento de crianças e adolescentes com câncer. Após a conclusão de todas as etapas, os pesquisadores se reuniram para discutir as mudanças propostas. Ao final do processo de adaptação cultural do Adolescent Pediatric Pain Tool, todos os 67 descritores da dor, propostos inicialmente, foram mantidos em sua versão em português.

Conclusão: as etapas do processo de adaptação cultural do Adolescent Pediatric Pain Tool foram alcançadas e sua descrição detalhada de forma a evidenciar o rigor na condução do estudo.

DESCRITORES: Adolescente. Criança. Neoplasias. Dor. Estudos de validação.

\section{ADAPTACIÓN CULTURAL DEL INSTRUMENTO ADOLESCENT PEDIATRIC PAIN TOOL PARA NIÑOS Y ADOLESCENTES BRASILEÑOS CON CÁNCER}

\section{RESUMEN}

Objetivo: describir las etapas realizadas en el proceso de adaptación cultural del instrumento de evaluación del dolor Adolescent Pediatric Pain Tool, para niños y adolescentes brasileños con cáncer.

Método: se trata de un estudio metodológico y transversal. Las etapas recorridas del proceso de adaptación cultural del instrumento hasta la validación semántica siguieron un método adaptado que comprendió: traducción inicial, síntesis de las traducciones, evaluación por el Comité de Especialistas, retrotraducción, comparación con el instrumento original y validación semántica propiamente dicha.

Resultados: el proceso de traducción inicial del instrumento hasta la obtención del consenso final tardó, aproximadamente, cuatro meses. En la etapa de evaluación por el Comité de Especialistas, participaron del estudio tres profesionales del área de la salud, con conocimiento en la temática y dominio de la lengua inglesa. Para la etapa de validación semántica, participaron 35 niños y adolescentes de ocho a 18 años incompletos, atendidos en la institución donde se realizaban el tratamiento y el seguimiento de niños y adolescentes con cáncer. Después de la conclusión de 
todas las etapas, los investigadores se reunieron para discutir los cambios propuestos. Al final de la adaptación cultural del instrumento Adolescent Pediatric Pain Tool, los 67 descriptores del dolor, propuesto inicialmente se mantuvieron en su versión portuguesa.

Conclusión: las etapas del proceso de adaptación cultural del Adolescent Pediatric Pain Tool se alcanzaron y su descripción detallada, para evidenciar el rigor en la conducción del estudio.

DESCRIPTORES: Adolescente. Niño. Neoplasias. Dolor. Estudios de validación.

\section{INTRODUCTION}

Chronic conditions are health problems that demand continuing care, lasting several years or decades. They are increasing all over the world and no country is exempted from the impact these conditions cause. ${ }^{1}$ The chronic conditions include cancer, which represents one of the main public health problems globally, being present across all cultures, ethnic groups, genders and age ranges, including children and adolescents. Approximately 160,000 new cases and 90,000 deaths due to cancer are estimated per year, ${ }^{2}$ with 12,600 new cancer cases in children and adolescents up to 19 years of age in Brazil in 2015/2016. ${ }^{3}$

In view of the high incidence of child-juvenile cancer, these patients' quality of life should be considered, as pain is a frequent symptom associated with cancer. Specific pain treatment centers in developed countries indicate that all children with cancers experience pain related to their disease or the treatment, with more than $70 \%$ of them presenting severe pain at some moment. ${ }^{4}$ Despite concerns with pain relief in children, this pain is often not acknowledged and may be treated inappropriately, even when sufficient resources are available. ${ }^{5}$

Successful pain treatment requires a careful assessment of its nature, understanding of the different pain types and patterns and knowledge on the best treatment. Proper pain assessment as soon as it emerges will serve as a baseline to judge subsequent interventions. ${ }^{6}$

To promote good pain management, the first step is its assessment and measuring, keeping in mind that managing this kind of problem is difficult without a measure to support the treatment or therapeutic conduct. Therefore, several methods have been developed to measure the pain perceived and felt. ${ }^{7}$ Among the pain assessment methods, multidimensional tools are employed to assess and measure the different pain dimensions, based on response indicators and their interactions. The main dimensions assessed are the sensory, affective and evaluative. ${ }^{8}$

In the Brazilian literature, there is a lack of specific tools for pain assessment in children and adolescents. Although internationally available, the tools can not be used in our context as, to obtain a valid and reliable tool for application in a culture different from the culture it was built for, a mere translation is insufficient. Instead, steps have to be executed that are rigorously grounded on a consolidated method. To validate a measure, following a method is essential to make the tool as reliable as possible in relation to the original one. ${ }^{9}$

The adaptation process of an existing measure from one culture to another has been widely used in various knowledge areas, ${ }^{9}$ mainly in multinational and multicultural health research, in which tools need to be adapted to other languages than the target language. ${ }^{10}$ This practice has evidenced the saving of time, staff and financial resources, besides permitting the comparison of data among the different cultures the tools were applied in. ${ }^{11}$

The objective in this study is to describe the steps in the cross-cultural adaptation process of the Adolescent Pediatric Pain Tool (APPT) for Brazilian children and adolescents with cancer. This 
multidimensional tool has only been validated in English and serves to assess the location, intensity and quality of pain in children and adolescents aged between eight and 18 unfinished years old. The choice of the APPT is justified by the authors' careful description of the aspects involved in its construction process, particularly the sample composition of child and adolescent participants, besides the detailing of each step in the validation process, which disclosed the rigorous execution of the studies that culminated in the publication of the tool. ${ }^{12-16}$

In the APPT, the child or adolescent locates the pain by means of a graphical representation of the human body, front and back, identifying the left and right sides, where the child is expected to mark the body area where (s)he feels pain. ${ }^{12-13}$ The pain intensity is assessed on a scale, consisting of a straight ten-centimeter horizontal line with five anchors (no pain, little pain, medium pain, large pain and worst possible pain), ${ }^{15}$ where the child is expected to mark the pain intensity by drawing a top-down line. Finally, the child assesses the pain quality from a list of 67 pain descriptors that join the sensory, affective, evaluative and temporal dimensions. ${ }^{13,16}$

\section{METHOD}

This methodological and cross-sectional study ${ }^{17}$ is part of a cooperative multicenter project with foreign participation. The objective is to develop the cultural adaptation and validation of the APPT for Portuguese in Brazil and in Portugal, publishing, after its validation in each context, a valid and reliable tool to measure pain in children and adolescents with cancer whose first language is Portuguese. Researchers from Brazil, Portugal and the United States participate in the study, the latter of which serves as the research coordination center. In view of the characteristics of the project this research is affiliated with, this study was submitted to the evaluation of the Ethics Committee for Research involving Human Beings.

In compliance with the guidelines of National Health Council Resolution 196/96, ${ }^{18}$ in force at the time the study was developed, all members of the Expert Committee and all mothers and/or legal caregivers for the child or adolescent signed the Informed Consent Form, before the start of the data collection, during Expert Committee steps I and II and during the semantic validation of the tool, respectively. In addition, the children and adolescents' assent was request, out of respect and consideration for their participation.

The choice of the adapted method consisted of the development of the back-translation after the Expert Committee assessment, as observed in the method of The Disabkids Group. ${ }^{19}$ In accordance with the methodological option of one of the author groups,,$^{10}$ the back-translation phase takes place immediately after the consensus version of the initial translations. We also chose to include the semantic validation phase, present in the method of The Disabkids Group. ${ }^{19}$

To develop this study, we decided to use an adapted method, proposed by the research team responsible for this study, which combines the guidelines of two reference groups. ${ }^{10,19}$ The adapted method was chosen to include the Expert Committee assessment phase in the adaptation process. ${ }^{10}$ Thus, after the literal translation of the word or expression, the experts who participated in this phase considered the semantic, conceptual, idiomatic and cultural equivalences, ${ }^{10}$ enhancing the rigor of the cross-cultural adaptation process.

The phases developed in this research are displayed in Table 1 below and detailed in the results of this study. 
Table 1 - Cross-cultural adaptation phases of the Adolescent Pediatric Pain Tool for Brazilian Portuguese

\begin{tabular}{|c|c|}
\hline Phases & Participants \\
\hline $\begin{array}{l}\text { Initial translation from English to Portuguese (two } \\
\text { versions) }{ }^{10,19}\end{array}$ & $\begin{array}{l}\text { Bilingual members of the research group } \\
\text { (Portuguese and English) }\end{array}$ \\
\hline Consensus between translations (one version) ${ }^{10,19}$ & All five researchers involved in the study \\
\hline $\begin{array}{l}\text { Assessment by Expert Committee I (three } \\
\text { versions) }\end{array}$ & $\begin{array}{l}\text { Three researchers external to the study, } \\
\text { bilingual, engaged in the research theme }\end{array}$ \\
\hline $\begin{array}{l}\text { Synthesis of suggestions by Expert Committee } \\
\text { (one version) })^{10}\end{array}$ & All research members engaged in the study \\
\hline $\begin{array}{l}\text { Assessment by Expert Committee II (three } \\
\text { versions) }\end{array}$ & $\begin{array}{l}\text { The same three researchers who participated } \\
\text { in Assessment by Expert Committee I }\end{array}$ \\
\hline Final consensus (one version) $)^{10}$ & All five researchers involved in the study \\
\hline $\begin{array}{l}\text { Back-translation from Portuguese to English (two } \\
\text { versions) }{ }^{10,19}\end{array}$ & $\begin{array}{l}\text { Two bilingual professionals (Portuguese and } \\
\text { English) unfamiliar with the research objective }\end{array}$ \\
\hline $\begin{array}{l}\text { Consensus between back-translations (one } \\
\text { version) }{ }^{10,19}\end{array}$ & All researchers involved in the study \\
\hline $\begin{array}{l}\text { Comparison between original English version and } \\
\text { back-translation (one version) }\end{array}$ & All researchers involved in the study \\
\hline $\begin{array}{l}\text { Final version of APPT in Portuguese (one } \\
\text { version) } \text { ) }^{10,19}\end{array}$ & All researchers involved in the study \\
\hline $\begin{array}{l}\text { Semantic validation involving children and } \\
\text { adolescents with cancer (three phases) }{ }^{19}\end{array}$ & $\begin{array}{l}35 \text { children and adolescents with cancer } \\
\text { between eight and } 18 \text { unfinished years }\end{array}$ \\
\hline
\end{tabular}

The semantic validation phase took place at the chemotherapy center, outpatient clinic and pediatric wards of a teaching hospital in the city of Ribeirão Preto-SP, where children and adolescents with cancer are treated and monitored. We recruited a sample of 35 children and adolescents with cancer in different treatment stages of the disease. In this phase, we set the following inclusion criteria: children and adolescents between eight and 18 unfinished years old diagnosed with cancer, accompanied by their mother or responsible caregivers and able to understand the questions in the tool. The exclusion criteria were: children and adolescents without clinical conditions to participate, who were in pain at the time of the interview or who were submitted to painful procedures on the occasion of the data collection, assessed based on data from the patient history and information by the health team.

To define the sample size of the children and adolescents with cancer who participated in this phase, we used the guidelines in The Disabkids Group method. ${ }^{19}$ First, the 67 pain descriptors translated from the APPT were divided in four semantic validation tables, three of which contained 17 and the fourth 16 descriptors. The choice to divide the tool in subsectors was due to its size, as the assessment of all words and expressions by all children and adolescents selected for the study could make them feel tired, compromising their results. ${ }^{19}$ In the first semantic validation phase, in total, 24 children and adolescents participated, being half of the sample between eight and 12 years old and the other half between 13 and 18 unfinished years old, equitably divided between boys and girls.

In the second semantic validation phase, three children between eight and 12 years old and three adolescents between 13 and 18 unfinished years old participated, male and female, within each age group. In the third phase, two children between eight and 12 years old and three adolescents between 13 and 18 unfinished years old participated, male and female. At the end of the three phases, in total, 35 children and adolescents with cancer had been recruited. 


\section{RESULTS}

\section{Initial translation and consensus version}

The process from the initial translation of the tool until reaching the final consensus took approximately four months. The first phase in the cross-cultural adaptation of the APPT was the initial translation from English to Portuguese. In that sense, three members of the research group independently developed two translations of the tool. In this phase, all researchers involved in the translations were native Portuguese speakers with in-depth knowledge of the English language.

After the translations, all APPT instructions and pain descriptors were organized so that, considering the two versions of the translated tool, the similarities and differences in each term or expression could be discussed in the entire group of researchers involved in this study, with a view to reaching a consensus version (Consensus Portuguese I).

To obtain the first consensus version, different face-to-face (among the Brazilian researchers) and online meetings (among all researchers involved in the study) were held. During the online meetings, the presence of the research team from the United States was very relevant, as the help of native speakers like the general coordinator of the project, permitted understanding the particularities of similar terms, such as beating and throbbing, translated as pulsante and latejante, respectively.

\section{Expert Committee}

To verify the semantic (equivalence between meanings of words), idiomatic (equivalence of idiomatic and colloquial expressions), cultural (experiences characteristic of each culture) and conceptual (concepts and meanings of the words in the different cultural contexts) equivalences, ${ }^{9}$ the translated version of the APPT was forwarded to health professionals with profound knowledge on the theme and the English language in order to compare the original and the translated tool. This part of the research took place in two phases, called Expert Committee I and Expert Committee II.

\section{Expert Committee I}

After the first consensus version in Portuguese had been reached, this version of the tool was forwarded to three health professionals, being two nurses and one psychologist, who were knowledgeable on the theme and mastered the English language. With the original and translated tools at hand, all members of the Expert Committee, who readily agreed to participate in the study, received instructions on the equivalences: semantic, idiomatic, cultural and conceptual, ${ }^{9}$ so as to allow them to assess the translated tool appropriately.

After the Expert Committee members' suggestions, in the first phase, all researchers responsible for the development of this study met to discuss the disagreements about the results. The experts' proposals were organized to permit comparisons among these suggestions, followed by the elaboration of a new translated version of the tool (Synthesis of Expert Committee's suggestions).

\section{Expert Committee II}

The final version, resulting from Expert Committee I, was again submitted to the same experts for assessment. This phase was intended to check whether the suggestions concerning the consensus version from the first phase had been accepted. As a result of this activity, one of the experts indicated she had no further suggestions; the other two contributed with new suggestions.

Based on the Expert Committee members' contributions and using a synthesis worksheet of all suggestions, a discussion meeting was held for all research team members to more accurately understand the descriptors which, according to the Expert Committee, were being used with meanings 
different from the original tool. After this discussion, when the entire team analyzed all words for with the Expert Committee had suggested modification, proposing changes when necessary, we reached a new version of the translated tool (Final consensus).

\section{Back-translation}

To check whether the tool had been properly translated, maintaining the meaning of the words in the original tool, its translated version was back-translated into English. In this phase, two independent translators, who spoke English fluently and were knowledgeable on the English language but were not familiar with the tool translated the final consensus version into English. With the two back-translated versions at hand, the research team met online, all words were compared one by one and synthesized in a single version. Then, the back-translated tool was forwarded to the author of the original tool to assess whether new translations were needed or the same translations could be maintained.

\section{Comparison between back-translated version and original tool}

Most translations were similar to the original tool, but some diverging terms and expressions were discussed among all team members engaged in the translation (e.g.: aching, like an ache and like a hurt). In this phase, the opinion of the primary author of the tool was taken into account to elaborate the final version of the APPT in Portuguese. With the final version at hand, those terms that needed modification were again forwarded to the two translators who had elaborated the back-translation. They confirmed that the new translations were correct.

\section{Semantic validation}

The semantic validation process took place at three distinct times, using a tool elaborated for this purpose. In total, 35 children and adolescents with cancer participated, being 17 between eight and 12 years of age, and 18 adolescents between 13 and 18 unfinished years. Overall, the children and adolescents who participated in this study presented varying tumors, but the most frequent were leukemia $(25.7 \%)$, central nervous system tumors $(22.9 \%)$, bone tumors $(22.9 \%)$ and lymphomas $(20.0 \%)$.

The questions formulated were intended to identify whether the children and adolescents knew the expressions or words in the APPT, whether they experienced difficulties to understand them and whether they used them to describe their own pain. In situations in which they mentioned knowing them but did not use them to describe their pain, they could suggest a new word they used with the same meaning as the first.

As a criterion to include the words and expressions in the final tool, more than $50 \%$ of the sample of children and adolescents who participated in the study should know them. If more than $50 \%$ of the sample knew the word in only one group (children or adolescents), it was considered as unknown by the entire group, demanding a new semantic validation phase for both groups. This criterion was adapted from the construction process of the APPT, when the authors considered that, to be included in the tool, more than $50 \%$ of the child and adolescent sample should know the word. ${ }^{16}$

The words unknown to more than $50 \%$ of the sample of children and adolescents demands a new semantic validation phase. In some of these situations, the participants proposed new words, when were assessed by the research group and then submitted for assessment by another sample of children and adolescents. Until the achievement of the final consensus, when more than $50 \%$ of the child and adolescent sample knew all words, three semantic validation phases were necessary. In 
the first phase, 27 children and adolescents participated; in the second, six children and adolescents and, in the third, five children and adolescents.

At the end of the first semantic validation phase, out of the 67 descriptors in the pain quality assessment in the APPT, most of the child and adolescent participants knew 52 (77.6\%). The remaining $15(22.4 \%)$ were identified as unknown to the children and adolescents.

The 15 descriptors identified as unknown by children and adolescents were reconsidered. For those descriptors for which the participants in the first semantic validation phase proposed new meanings, the latter substituted the former, with the research team's consensus. The remainder was maintained to check their acceptance by a new sample of children and adolescents.

At the end of the second semantic validation phase, seven words were still unknown. Therefore, the research team suggested new alternatives for all of these words and tested them in a new sample of children and adolescents in the third validation phase. In that phase, all interviewees knew all words, so that the semantic validation phase of the APPT was concluded.

\section{DISCUSSION}

Vast literature exists today about aspects of the assessment and measuring of child-juvenile pain, but the complexity of the theme requires that certain factors be considered, such as the age, sex and type of condition. Despite the existence of many tools for pain assessment in children, some studies present limitations in terms of the sample, and others in the assessment of the psychometric properties of the tools. ${ }^{20}$ In addition, most studies were developed in the United States and Canada, entailing the need to assess the reliability and validity of the tools when used in other populations from different cultures. ${ }^{21}$ All of these aspects should be taken into account in the choice of a certain pain measure. The context in which the pain emerges should also be considered, such as pediatric oncology for example, being a multidimensional experience, and its management also involves cultural aspects of the cancer experience in such an early phase of the lifecycle.

To assess pain in children and adolescents, studies have been developed. According to the systematic literature review, ${ }^{22}$ to measure and interpret pain in children, aspects of the subjects' temporality and individuality need to be considered, the child's social communication and cognitive skills, the ability to use self-reported pain scales and children unable to use such tools, such as children under six years of age.

In the choice of the APPT, we took into account the authors' careful description of the aspects involved in its construction process, ${ }^{12-16}$ particularly the composition of the child and adolescent sample, besides the detailing of each phase in the validation process, which disclosed the rigor of the studies that culminated in the publication of the tool. In addition, the APPT is a multidimensional pain assessment tool that combines the sensory, affective, evaluative and temporal dimensions with the careful assessment of the pain location and intensity.

Different studies have been conducted using the APPT to assess children and adolescents' pain in various chronic and acute pain conditions, having supported English speaking health and research teams to assess their patients' pain. ${ }^{23}$

The need to cross-culturally adapt the APPT to the Portuguese language was mainly due to the lack of validated and reliable tools for pain assessment in children and adolescents with cancer in the Brazilian context. In that scenario, the translation and cross-cultural adaptation of the APPT are very important to provide health professionals with a highly specific tool to assess pain in that population.

Besides contribution to the availability of a valid tool for pain assessment in children and adolescents with cancer, we hope to propose guidelines for new cross-cultural adaptation studies of tools. In that sense, specifying the phases and the researchers' rigor to comply with each was one of the priorities. The adaptation process of the APPT until the back-translation phase took approximately 
18 months as, in each phase, exhaustive discussions were needed, involving the entire research team, in order to guarantee the rigor of the study, maintaining the characteristics of the initial tool but keeping in mind the particularities of the context it was being adapted to.

To achieve a valid and reliable tool for use in a different culture than what it was constructed for, the entire process deserves an equal degree of attention, from the initial translation until the field study. Dedicating time to the translation process may mean future savings of time and resources, as a translation that exactly reflects the reality of the target population can result in success in future phases, such as the semantic validation. To validate a tool, a method needs to be followed that reflects the transparency of the process and permits demonstrating its validity and reliability.

No consensus exists yet on the best method to accomplish a cross-cultural adaptation of a tool, ${ }^{9}$ particularly due to the limited number of studies of this kind in pediatric oncology. In that sense, the detailed definition and description of the phases to be executed are valid to contribute to methodological studies, specifically validation studies of research tools. In this study, we chose to combine the guidelines of two reference groups, ${ }^{10,19}$ including steps and changes in their order, so that the back-translation was the final phase. That is in line with other authors, ${ }^{21}$ in the adaptation process of the self-perceived health assessment tool by children between six and 11 years of age, the Child Health and IIIness Profile-Child Edition, from English to Spanish. In choosing this sequence, we intended to accomplish the back-translation phase with a version of the tool that truly reflected the particularities of the target context while preserving the characteristics of the original tool. This decision also made it possible to optimize the human and financial resources available to validate the tool.

Although the cross-cultural adaptation process of the APPT was concluded, culminating in the version APPT-P-Brazil, it can only be used for pain assessment in children and adolescents with cancer after the conclusion of the validation process, in a subsequent phase. For the validation process of the APPT-P-Brazil, its psychometric properties need to be assessed to make it applicable for pain assessment in children and adolescents with cancer.

We also highlight that, despite the pain assessment using validated tools for this purpose, it is important for health professionals to be sensitive and develop skills to articulate and share their own knowledge with their patients and caregivers, permitting the dialogue with those clients, with a view to achieving comfort measures that present the best pain relief results. ${ }^{24}$

In this process, we consider that the semantic validation involving children and adolescent recruited from a single health institution can represent a limitation, as the Brazilian regional differences may not be represented in the study sample.

\section{CONCLUSION}

The cross-cultural adaptation and validation of tools are important strategies to publish valid and reliable tools for use in different contexts. Particularly the construction of new pain measures and assessment tools demands costs and time, which may not be feasible. In this case, the phases of the cross-cultural adaptation process of the APPT, which included the translation, back-translation, Expert Committee assessment and semantic validation were achieved and their detailed description evidenced the rigorous development of the study.

To grant non-traumatic care to the children and adolescent with cancer, global pain assessment is needed. In that sense, the availability of the APPT-Brazil, after the conclusion of the validation process, will provide the health professionals with useful information about the pain children and adolescents are feeling, helping them to propose effective interventions to relieve these children and adolescents' pain, minimizing their suffering and that of their relatives. 
In a subsequent phase, the translated APPT will be submitted to be validation process, assessing its psychometric properties to adapt it for use in research and clinical practice. Therefore, the APPT cannot be applied yet in the target population and future studies are needed to develop its validation.

\section{REFERENCES}

1. Organização Mundial da Saúde. Cuidados inovadores para condições crônicas: componentes estruturais de ação: relatório mundial. Brasília, DF: OMS; 2003.

2. World Health Organization. World Cancer Report 2008. Geneva: OMS; 2008. Available from: https://www.who.int/cancer/publications/world_cancer_report2008/en/

3. Instituto Nacional de Câncer (BR). Estimativa 2016: incidência de câncer no Brasil. Rio de Janeiro: Instituto Nacional de Câncer; 2015. Available from: https://www.inca.gov.br/campanhas/ dia-nacional-de-combate-ao-cancer/2015/estimativa-2016-incidencia-de-cancer-no-brasil

4. Instituto Nacional de Câncer (BR). Estimativa 2006: incidência de câncer no Brasil. Rio de Janeiro: Instituto Nacional de Câncer; 2005.

5. World Health Organization. Cancer pain relief and palliative care in children. Geneva: OMS; 1998. Available from: https://apps.who.int/iris/handle/10665/42001

6. Ministério da Saúde (BR). Cuidados paliativos oncológicos: controle da dor. Rio de Janeiro: Instituto Nacional de Câncer; 2001.

7. Tomlinson D, VonBaeyer CL, Stinson JN, Sung L. A systematic review of faces scales for the self-report of pain intensity in children. Pediatrics [Internet]. 2010 [cited 2016 Feb 05];126(5):116898. Available from: https://doi.org/10.1542/peds.2010-1609

8. Sousa FAEF. Dor: o quinto sinal vital. Rev Latino-Am Enfermagem [Internet]. 2002 [cited 2016 Feb 05];10(3):446-7. Available from: http://dx.doi.org/10.1590/S0104-11692002000300020

9. Guillemin F, Bombardier C, Beaton D. Cross-cultural adaptation of health-related quality of life measures: literature review and proposed guidelines. J Clin Epidemiol. 1993;46(12):1417-32. Available from: https://doi.org/10.1016/0895-4356(93)90142-N

10. Beaton DE, Bombardier C, Guillemin F, Ferraz MB. Guidelines for the process of cross-cultural adaptation of self-report measures. Spine. 2000;25(24):3186-91. Available from: https://doi. org/10.1097/00007632-200012150-00014

11. Cummings $S R$, Stwart $A$, Hulley $S B$. Elaboração de questionários e instrumentos de coleta de dados. In: Hulley SB, Cummings SR, Browner WS, Grady D, Hearst N, Newman TB, eds. Delineando a pesquisa clínica: uma abordagem epidemiológica. Porto Alegre, RS: Artmed; 2003:265-81.

12. Savedra MC, Tesler MD, Holzemer WL, Wilkie DJ, Ward JA. Pain location: validity and reliability of body outline markings by hospitalized children and adolescents. Res Nurs Health. 1989;12(5):30714. Available from: https://doi.org/10.1002/nur.4770120506

13. Savedra MC, Holzemer WL, Tesler MD, Wilkie DJ. Assessment of postoperation pain in children and adolescents using the adolescent pediatric pain tool. Nurs Res. 1993;42(1):5-9. Available from: https://doi.org/10.1097/00006199-199301000-00002

14. Savedra MC, Tesler MD, Holzemer WL, Brokaw P. A strategy to assess the temporal dimension of pain in children and adolescents. Nurs Res. 1995;44(5):272-6. Available from: https://doi. org/10.1097/00006199-199509000-00003 
15. Tesler MD, Savedra MC, Holzemer WL, Wilkie DJ, Ward JA, Paul SM. The word-graphic rating scale as a measure of children's and adolescents' pain intensity. Res Nurs Health. 1991;14(5):36171. Available from: https://doi.org/10.1002/nur.4770140507

16. Wilkie DJ, Holzemer WL, Tesler MD, Ward JA, Paul SM, Savedra MC. Measuring pain quality: validity and reliability of children's and adolescents' pain language. Pain. 1990;41(2):151-9. Available from: https://doi.org/10.1016/0304-3959(90)90019-A

17. LoBiondo-Wood G, Haber J. Pesquisa em enfermagem: métodos, avaliação crítica e utilização. 4th ed. Rio de Janeiro: Guanabara-Koogan; 2001.

18. Brasil. Ministério da Saúde. Conselho Nacional de Saúde. Resolução $n^{\circ} 196$ de 10 de outubro de 1996. Estabelece as diretrizes e normas regulamentadoras de pesquisas envolvendo seres humanos. Brasília, DF, 10 de outubro de 1996.

19. The Disabkids Group. Translation \& validation procedure: guidelines and documentation form. Lengerich: Pabst Science Publishers; 2004. Available from: https://www.disabkids.org/licensingand-use/validation-guidelines/

20. Silva JA, Ribeiro-Filho NP. Avaliação e mensuração de dor: pesquisa, teoria e prática. Ribeirão Preto, SP: FUNPEC; 2006.

21. Rajmil L, Serra-Sutton V, Estrada MD, Fernandez de Sanmamed MJ, Guillamón L, Riley A, et al. Adaptación de la versión española del perfil de salud infantil (Chile Health and Illness Profile-Child Edition, CHIP-CE). An Pediatr (Barc) [Internet]. 2004 [cited 2016 Feb 05];60(6):522-9. Available from: https://doi.org/10.1016/S1695-4033(04)78321-6

22. von Baeyer CL. Children's self report of pain intensity: what we know, where we are headed. Pain Res Manag. 2009;14(1):39-45. Available from: https://doi.org/10.1155/2009/259759

23. Fernandes $A M$, De Campos $C$, Batalha $L$, Perdigão $A$, Jacob $E$. Pain assessment using the Adolescent Pediatric Pain Tool: a systematic review. Pain Res Manag [Internet]. 2014 [cited 2016 Feb 05];19(4):212-8. Available from: https://doi.org/10.1155/2014/979416

24. Rocha AFP, Sposito AMP, Bortoli PS, Silva-Rodrigues FM, Lima RAG, Nascimento LC. Oncologic pain relief: strategies told by adolescents with cancer. Texto Contexto Enferm [Internet]. 2015 Jan-Mar [cited 2016 Feb 05];24(1):96-104. Available from; https://doi.org/10.1590/010407072015002120013 


\section{NOTES}

\section{CONTRIBUTION OF AUTHORITY}

Study design: De Bortoli PS, Jacob E, Fernandes AM, Nascimento LC

Data analysis and interpretation: De Bortoli PS, Jacob E, Castral TC, Santos CB, Fernandes AM, Nascimento LC

Writing and / or critical review of content: De Bortoli PS, Castral TC, Nascimento LC

Review and final approval of the final version: De Bortoli PS, Castral TC, Santos CB, Nascimento LC

\section{ETHICS COMMITTEE IN RESEARCH}

Approved by the Ethics Committee in Research (ECR) with Human Beings of the Hospital das Clínicas, Faculdade de Medicina de Ribeirão Preto, Universidade de São Paulo (HCFMRP-USP), after having received Institutional Review Board approval from the coordination center in the United States. Approval from the ECR at HCFMRP-USP was obtained, process 13688/2009, after which the study was forwarded to the Brazilian National Research Ethics Committee (CONEP), as it involves foreign participation, and was approved (CONEP register 15850).

\section{CONFLICT OF INTEREST}

There is no conflict of interest.

\section{HISTORICAL}

Received: April 29, 2016.

Approved: October 25, 2016.

\section{CORRESPONDENCE AUTHOR}

Lucila Castanheira Nascimento

lucila@eerp.usp.br 